\title{
Divertículo de Meckel con tejido pancreático ectópico en un niño de 12 años con invaginación intestinal. Reporte de caso y revisión de la literatura
}

\author{
Meckel diverticulum with ectopic pancreatic tissue in a 12-year-old boy with intestinal \\ invagination. Case report and review of the literature
}

Sonia Guzmán-Martínez" *, Alfonso Galván-Montaño, Sonia Lara-Escalera², M. ${ }^{a}$ del Rocío Estrada Hernández ${ }^{3}$, Alejandro García-Peña ${ }^{4}$, Erika G. Castañeda-Ángeles ${ }^{3}$, Paulina Rojas-Muñoz y Silvia García-Moreno ${ }^{5}$

${ }^{1}$ Cirugía Pediátrica, Subdirección de Pediatría; ${ }^{2}$ División de Enseñanza; ${ }^{3}$ División de Anatomía Patológica; ${ }^{4}$ Departamento de Imagenología Diagnóstica y Terapéutica; ${ }^{5}$ División de Investigación Clínica. Hospital General Dr. Manuel Gea González, Ciudad de México, México

\begin{abstract}
Resumen
Introducción: El divertículo de Meckel es un remanente del conducto onfalomesentérico y su prevalencia es del $2 \%$. Caso clínico: Niño de 12 años con dolor abdominal, acompañado de evacuaciones mucosanguinolentas y hematemesis, con masa en cuadrante inferior derecho. En la laparotomía quirúrgica se encontró invaginación, y se realizó desinvaginación y resección del divertículo de Meckel. Conclusión: La asociación de divertículo de Meckel con tejido pancreático heterotópico en niños es poco frecuente. Clínicamente, su principal manifestación es la invaginación intestinal en la literatura revisada, y el ultrasonido constituye el mejor estudio para el diagnóstico de invaginación intestinal, no así para el divertículo de Meckel o el tejido pancreático heterotópico, en los que la tomografía sería una opción.
\end{abstract}

PALABRAS CLAVE: Divertículo de Meckel. Tejido pancreático ectópico. Invaginación intestinal.

\begin{abstract}
Introduction: Meckel's diverticulum is a remnant of the omphalomesenteric duct and its prevalence is $2 \%$. Clinical case: A 12-yearold male with abdominal pain, accompanied by muco-sanguineous evacuations and hematemesis, with right lower quadrant mass. In the laparotomy, invasion was found; intussusception reduction and resection of the Meckel's diverticulum was performed. Conclusion: The association of Meckel's diverticulum with heterotopic pancreatic tissue in children is rare, its main manifestation is intussusception and ultrasound is an option for diagnosis.
\end{abstract}

KEY WORDS: Meckel diverticulum. Ectopic pancreatic tissue. Intussusception.

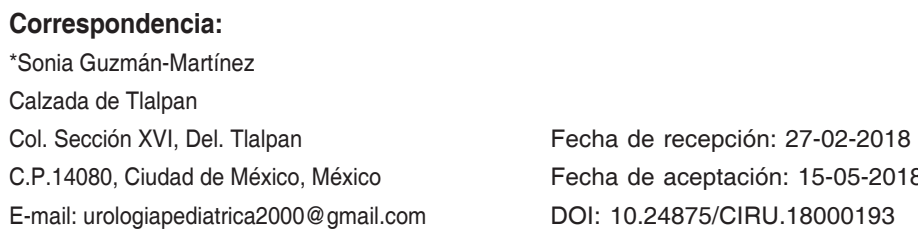

Cir Cir. 2018;86:450-454

Contents available at PubMed www.cirugiaycirujanos.com 


\section{Introducción}

El divertículo de Meckel es un remanente del conducto onfalomesentérico, localizado en el borde antimesentérico a 40-60 cm de la válvula ileocecal, y se caracteriza por tener todas las capas que se encuentran normalmente en el íleon ${ }^{1-3}$. La prevalencia del divertículo de Meckel es de aproximadamente el $2 \%$ en la población general; del total de los casos, el $76 \%$ son en adultos y el $24 \%$ en pacientes pediátricos ${ }^{2,3}$.

En un $62 \%$ se puede encontrar mucosa gástrica heterotópica, en el $6 \%$ tejido pancreático, en el $5 \%$ mucosa gástrica y pancreática, en el $2 \%$ mucosa yeyunal y en el $2 \%$ tejido de Brunner ${ }^{4}$. Clínicamente se puede manifestar con sangrado intestinal, dolor, oclusión intestinal o invaginación ${ }^{5}$. Es posible diagnosticarlo con gammagrafía con tecnecio 99 cuando existe mucosa gástrica ectópica, pero la tomografía computarizada es la que ha demostrado ser más específica mostrando una estructura tubular llena de líquido o bien imágenes de invaginación intestinal ${ }^{6}$.

El objetivo del presente trabajo es presentar un caso de divertículo de Meckel con tejido pancreático heterotópico en un niño de 12 años con invaginación intestinal, y realizar una revisión de la literatura, ya que es una patología poco frecuente y no encontramos casos reportados en la literatura nacional.

\section{Caso clínico}

Niño de 12 años con antecedente de apendicetomía laparoscópica a los 10 años de edad. Acude al servicio de urgencias por dolor abdominal de 8 horas de evolución, localizado en mesogastrio con intensidad 10/10, acompañado de evacuaciones mucosanguinolentas en siete ocasiones, que posteriormente fueron melénicas. Vómito en ocho ocasiones de contenido gastroalimentario y después con sangre. En la exploración física se observa presión arterial de $129 / 48 \mathrm{mmHg}$, presión arterial media de $73 \mathrm{mmHg}$, frecuencia cardiaca de 100 latidos por minuto, frecuencia respiratoria de 28 respiraciones por minuto, temperatura de $36{ }^{\circ} \mathrm{C}$, saturación del $86 \%$ y peso de $51 \mathrm{~kg}$. Deshidratado, consciente, orientado, mucosa oral pálida, campos pulmonares con adecuada entrada y salida de aire. Precordio con ruidos cardiacos aumentados en intensidad, sin soplos. Abdomen blando, depresible. Con diagnóstico de sangrado de tubo digestivo de etiología a determinar, se inició manejo con omeprazol, acetaminofeno y ondansetrón durante 48 horas, sin mejoría. Los estudios de laboratorio reportaron hemoglobina $15.00 \mathrm{~g} / \mathrm{dl}$, plaquetas 193,000 , leucocitos $10,600 \times 103 \mu \mathrm{L}$, neutrófilos $89.70 \%$, linfocitos $9.10 \%$, monocitos $1 \%$, basófilos $0.20 \%$, creatinina 0.82 , glucosa $128 \mathrm{mg} / \mathrm{dl}$, sodio 139 $\mathrm{mEq} / \mathrm{l}$, potasio $4.1 \mathrm{mEq} / \mathrm{l}$, calcio $9.40 \mathrm{mg} / \mathrm{dl} \mathrm{y}$ Proteína $C$ reactiva (PCR) $0.793 \mathrm{mg} / \mathrm{dl}$. Se realiza panendoscopia que no evidencia sangrado activo en el estómago ni en el esófago. Se solicita ultrasonido, ya que en la última exploración de abdomen se palpa una masa en el cuadrante inferior derecho, y reporta imagen en diana y líquido libre, sugestiva de invaginación. Se visualiza la cabeza de la invaginación en el ángulo hepático, identificando en el centro una imagen pediculada, redondeada, dependiente de un asa del intestino delgado (Fig. 1).

Con el diagnóstico de invaginación intestinal con más de 48 horas de evolución y considerando la edad del paciente, se decide efectuar una exploración quirúrgica, en la que se encuentra una doble invaginación: íleo-ileal e ileocólica (Fig. 2), el primer segmento íleo-ileal a expensas de un divertículo de Meckel invertido sobre su eje y este segmento doblemente invaginado al colon ascendente. Se llevan a cabo desinvaginación por taxis y resección intestinal del divertículo de Meckel localizado a $40 \mathrm{~cm}$ de la válvula íleo-cecal (Fig. 3), con $5 \mathrm{~cm}$ de intestino de cada lado y anastomosis término-terminal. La evolución posoperatoria fue favorable, por lo que el paciente se dio de alta sin complicaciones y hasta el momento del reporte se encuentra en buenas condiciones de salud.

En el estudio histopatológico, macroscópicamente se observa el divertículo de Meckel invaginado con sus tres capas y en el centro tejido de aspecto sólido, amarillo claro, que recuerda a tejido pancreático (Fig. 4). Al corte histológico se aprecian acinos pancreáticos y conductos ligeramente dilatados; no hay islotes de Langerhans (Fig. 5).

\section{Discusión}

El páncreas heterotópico se define como tejido pancreático sin una verdadera conexión anatómica o vascular con el páncreas, y fue reportado por primera vez por Jean-Schultz en $1729^{7,8}$. Otros términos usados son páncreas ectópico, páncreas accesorio y páncreas aberrante. En 1859, Zenker informó del primer caso de páncreas ectópico en un divertículo de Meckel $^{9}$. 


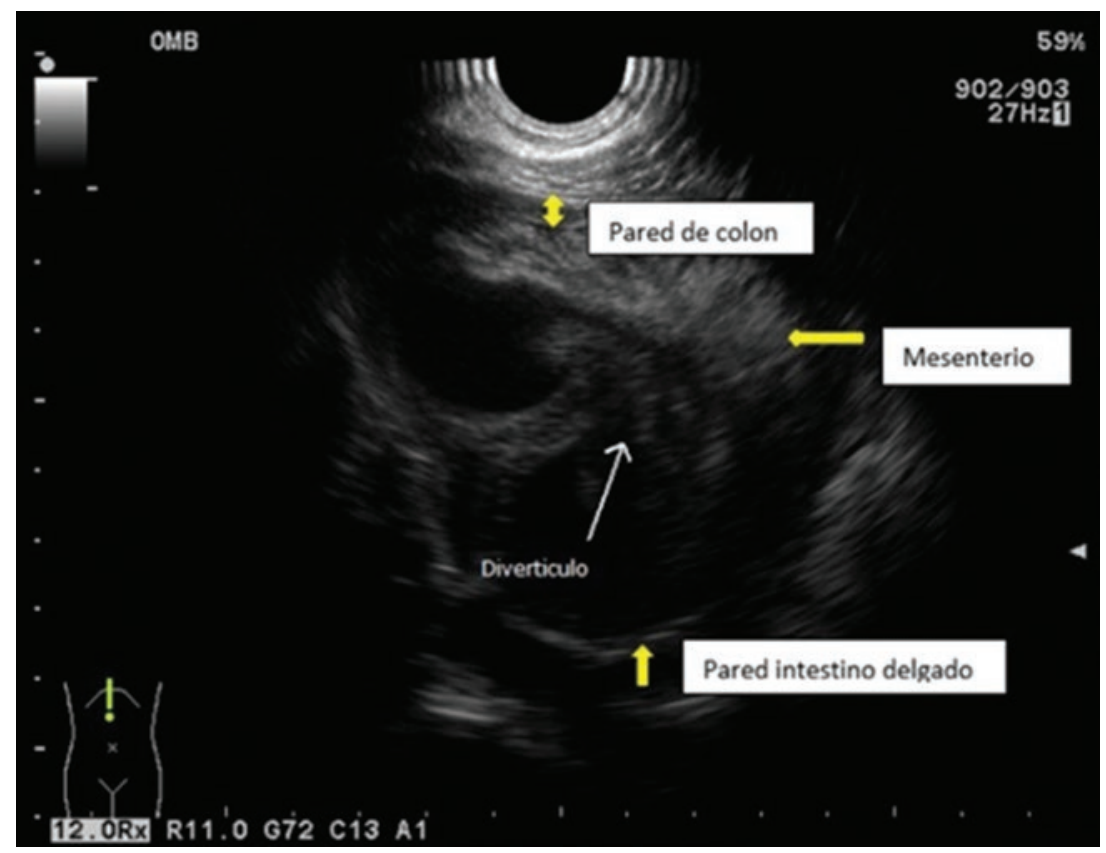

Figura 1. Ultrasonido abdominal en el que se visualiza la cabeza de la invaginación, identificando a nivel central en la cara lateral interna una imagen pediculada, redondeada, dependiente de un asa de intestino delgado.

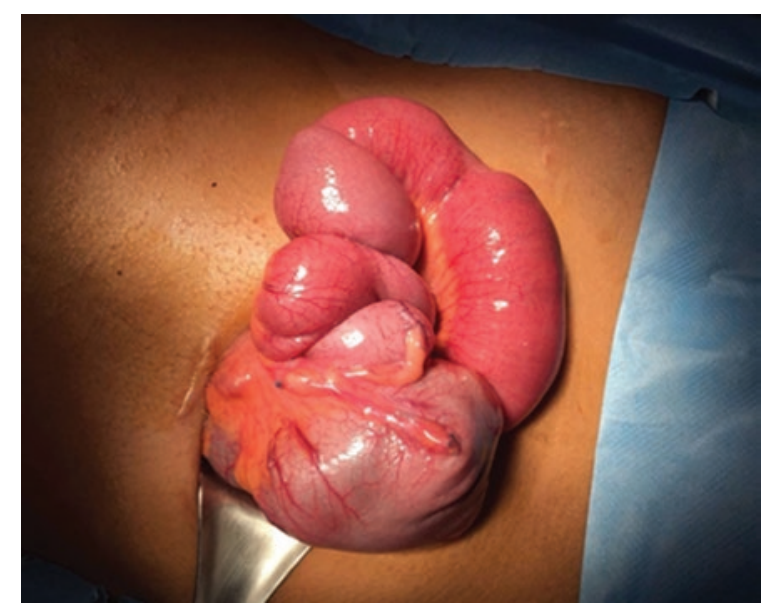

Figura 2. Doble invaginación intestinal: íleo-ileal e íleo-cólica.

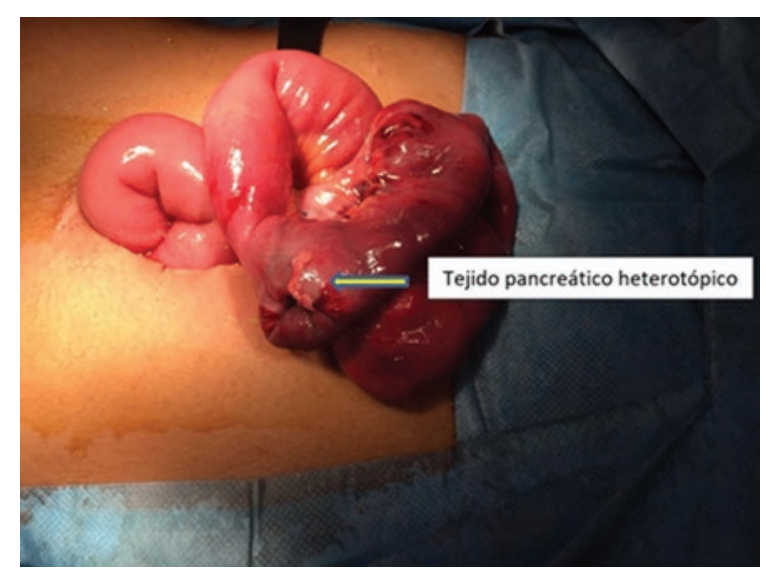

Figura 3. Divertículo de Meckel con tejido pancreático heterotópico.
Aún no está claro el origen, pero se cree que surge embrionariamente durante la rotación del intestino y la fusión del tejido pancreático dorsal y ventral, en donde una parte del tejido se separa del páncreas y se desarrolla en cualquier porción del intestino. Otra teoría más conocida se basa en la metaplasia pancreática del tejido endodérmico ${ }^{8,9}$. Debido a la proximidad de los brotes primordiales pancreáticos embrionarios y el intestino durante el desarrollo, el 70-90\% del páncreas ectópico queda en la parte superior del tubo digestivo ${ }^{10}$.

La mayoría de los pacientes con divertículo de Meckel son asintomáticos y el diagnóstico suele realizarse mediante gammagrafía con tecnecio 99, tomografía, endoscopia o durante exploraciones quirúrgicas realizadas por otras enfermedades. En los niños, la mayoría de los casos se detectan porque presentan invaginación intestinal. La visualización del tejido pancreático heterotópico es difícil y solo encontramos un reporte en que se logró identificar por ultrasonido el tejido pancreático heterotópico en el divertículo de Meckel como una masa homogénea, hipoecoica y bien definida ${ }^{11}$.

De acuerdo con los criterios de Heinrich, el páncreas heterotópico se clasifica en tipo 1 si contiene células de glándula exocrina, conductos excretores e islotes de Langerhans; en tipo 2 con glándulas excretoras y conductos excretores; y en tipo 3 si solo hay conductos excretores. El más frecuente es el tipo 2, seguido por 
Tabla 1. Casos documentados de niños desde los 23 días hasta los 15 años de edad con divertículo de Meckel y tejido pancreático heterotópico

\begin{tabular}{|c|c|c|c|c|}
\hline Autor, año & Edad & Sexo & Presentación & Clasificación histopatológica \\
\hline Guanà et al. ${ }^{6}, 2014$ & 7 años & Femenino & Invaginación & Tipo 1 \\
\hline $\begin{array}{l}\text { Baysoy et al. }{ }^{15} \text {, } \\
2010\end{array}$ & 5 años & Masculino & Invaginación & Desconocida \\
\hline Xiao et al. $.^{5}, 2009$ & 12 años & Masculino & Invaginación & Tipo 2 \\
\hline Huml et al. ${ }^{16}, 2009$ & 1 mes & Masculino & Dolor, náusea y vómito & Tipo 1 \\
\hline Ogata et al. ${ }^{17}, 2007$ & $\begin{array}{l}1 \text { año } \\
4 \text { años } \\
10 \text { años } \\
23 \text { días }\end{array}$ & $\begin{array}{l}\text { Femenino } \\
\text { Femenino } \\
\text { Masculino } \\
\text { Masculino }\end{array}$ & $\begin{array}{l}\text { Divertículo de Meckel, malrotación del intestino } \\
\text { Invaginación } \\
\text { Divertículo de Meckel } \\
\text { Divertículo de Meckel, atresia de vías biliares }\end{array}$ & $\begin{array}{l}\text { Tipo } 1 \\
\text { Tipo } 2 \\
\text { Desconocida } \\
\text { Desconocida }\end{array}$ \\
\hline Orri et al. ${ }^{18}, 2006$ & 7 meses & Masculino & Invaginación & Desconocida \\
\hline Clog et al. $.^{20}, 1908$ & 12 años & Masculino & Distensión abdominal & Desconocida \\
\hline Caso actual & 12 años & Masculino & Invaginación & Tipo 2 \\
\hline
\end{tabular}

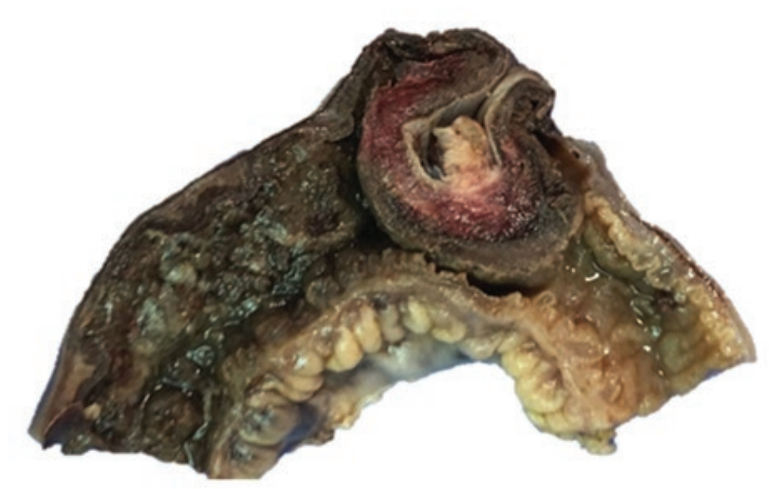

Figura 4. En el borde antimesentérico se observa el divertículo de Meckel invaginado con sus tres capas y en el centro tejido de aspecto sólido, amarillo claro, que recuerda a tejido pancreático.

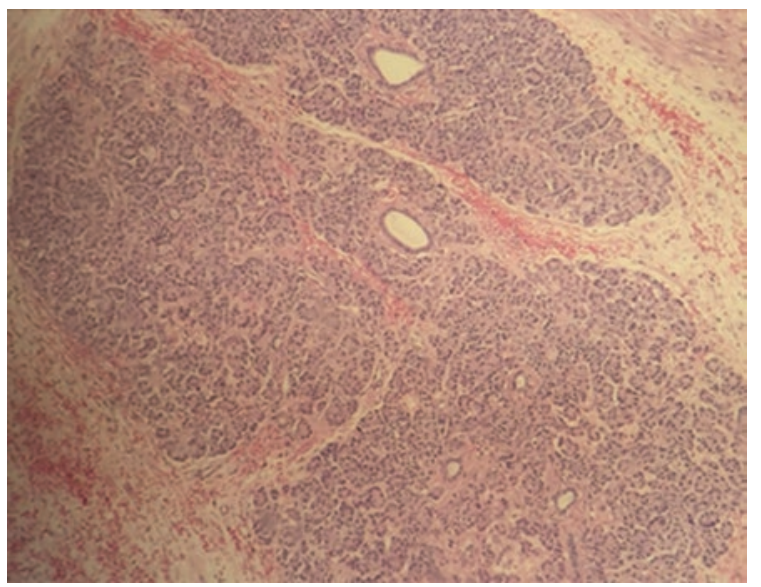

Figura 5. Corte histológico con acinos pancreáticos y conductos ligeramente dilatados. No hay islotes de Langerhans.

el tipo 1, mientras que el tipo 3 es infrecuente ${ }^{12-14}$. Nuestro caso correspondió al tipo 2.
En la revisión que realizamos pudimos documentar 10 casos reportados en niños desde los 23 días hasta los 15 años de edad, el $60 \%$ en mayores de 2 años y el $70 \%$ en varones (Tabla 1). Un $50 \%$ tuvo cuadro de invaginación, el $30 \%$ con divertículo de Meckel, y en dos casos se realizó laparotomía exploradora sin contar con un diagnóstico preciso, solo con la presencia de dolor abdominal, vómito o distensión abdominal. En cinco casos se reportó el tipo según la clasificación histológica de Heinrich, siendo los tipos 1 y 2 los más frecuentes $5,6,15-20$.

Consideramos que el tejido pancreático heterotópico favorece la presencia de invaginación intestinal, y también está referido que, si un paciente desarrolla pancreatitis aguda en el órgano "madre», la inflamación también afectará a los focos heterotópicos, causando dolor abdominal con elevación de enzimas pancreáticas en sangre, lo que no ocurrió en nuestro paciente ${ }^{14}$.

\section{Conclusiones}

La asociación de divertículo de Meckel con tejido pancreático heterotópico en niños es poco frecuente. Clínicamente, su principal manifestación es la invaginación intestinal en la literatura revisada. El ultrasonido constituye el mejor estudio para el diagnóstico de invaginación intestinal, pero no así para el divertículo de Meckel y el tejido pancreático heterotópico, en los que la tomografía sería una opción.

\section{Bibliografía}

1. Levy AD, Hobbs CM. Meckel diverticulum: radiologic features with pathologic correlation. Radiographics. 2004;24:565-87. 
2. Robustelli U, Manguso F, Armellino MF, Mannelli MP, Massa MR, Forner AL, et al. Acute symptomatic Meckel diverticulum management. Our experience on seven consecutive cases. Ann Ital Chir. 2014;85: 129-35.

3. Elsayes KM, Menias CO, Harvin HJ, Francis IR. Imaging manifestations of Meckel's diverticulum. AJR Am J Roentgenol. 2007;189:81-8.

4. Burjonrappa S, Khaing P. Meckel's diverticulum and ectopic epithelium: evaluation of a complex relationship. J Indian Assoc Pediatr Surg. 2014;19:85-9.

5. Xiao WD, Chen W, Yang H. Heterotopic pancreas within Meckel's diverticulum with obscure then massive gastrointestinal bleeding in a 12-yearold child: case report and review of the literature. J Int Med Res. 2009;37:967-72.

6. Guanà R, Bucci V, Carbonaro G, Cerrina A, Ferrero L, Teruzzi E, et al. Heterotopic pancreas in Meckel's diverticulum in a 7-year-old child with intussusception and recurrent gastrointestinal bleeding: case report and literature review focusing on diagnostic controversies. Afr J Paediatr Surg. 2014;11:354-8.

7. Pearson S. Aberrant pancreas. Review of the literature and report of three cases, one of which produced common and pancreatic duct obstruction. AMA Arch Surg. 1951;63:168-96.

8. Tanaka K, Tsunoda T, Eto T, Yamada M, Matsuo S, Izawa K. Diagnosis and management of heterotopic pancreas. Int Surg. 1993;78:32-5.

9. Okamoto H, Fujishima F, Ishida K, Tsuchida K, Shimizu T, Goto H, et al. Intraductal papillary mucinous neoplasm originating from a jejunal heterotopic pancreas: report of a case. Surg Today. 2014;44: 349-53.
10. Bromberg SH, Neto CC, Fernando A, Borger A, Franco MIF, Franca LCM, et al. Pancreatic heterotopias: clinicopathological analysis of 18 patients. Rev Col Bras Cir. 2010;37:413-9.

11. Monedero MD, Ripollés T, Nicolau MJ, Martínez-Pérez MJ. Pancreatic pseudotumor in Meckel diverticulum. Abdom Imaging. 2006;631:688-90.

12. Gunjača I, Mlinac-Lucijanic M, Pavlovic A, Gunjača M. Inflammation of ectopic pancreatic tissue as unusual case of duodenal perforation - a case report. Antropol. 2010;3:1119-22.

13. Heinrich H. Ein Beitrag Zur Histologie des Sogenakzessorischen Pancreas. Virchows. Arch Path Physiol. 1909;198:392-401.

14. Zarand A, Bajtai A, Baranyai Z, Dede K, Jakab F. Inflammation of ectopic pancreatic tissue in a Meckel's diverticulum causing acute abdominal symptoms: a case report and review of the literature. Int J Surg Pathol. 2011;19:359-63.

15. Baysoy G, Balamtekin N, Uslu N, Karavelioğlu A, Talim B, Özen H. Double heterotopic pancreas and Meckel's diverticulum in a child: do they have common origin? Turk J Pediatr. 2010;52:336-8.

16. Huml M, Sýkora J, Kobr J, Pizingerová K, Šebor J, Skála V, et al. Heterotopickýpankreas, ileokolickáinvaginace v kojeneckémvěku" Pediatr pro Praxi. 2009;10:191-2.

17. Ogata H, Oshio T, Ishibashi H, Takano S, Yagi M. Heterotopic pancreas in children: review of the literature and report of 12 cases. Pediatr Surg Int. 2008;24:271-5.

18. Orri TO, Ingibjorg G, Ronald M. Diagnosis and treatment of gastric heterotopic pancreas. World J Surg. 2006;30:1682-9.

19. Ormarsson OT, Gudmundsdottir I, Mårvik R. Diagnosis and treatment of gastric heterotopic pancreas. World J Surg. 2006;30:1682-9.

20. Clog H. Acute Intestinal Obstruction. Lancet. 1908;1:639. 